\title{
Video-assisted thoracic surgery assisted by articulated arm (AVATS): a new way towards ergonomics and optimization of surgical resources
}

\author{
Julio Sesma ${ }^{1}$, Sergio Bolufer ${ }^{1}$, Carlos Gálvez ${ }^{1}$, Melodie Álvarez ${ }^{1}$, Francisco Lirio ${ }^{2}$, Juan Manuel Córcoles ${ }^{3}$, \\ Jone Miren Del Campo ${ }^{1}$, Sergio Maroto ${ }^{1}$, María Galiana ${ }^{1}$, José Navarro-Martínez ${ }^{1}$, María Jesús Rivera ${ }^{1}$ \\ ${ }^{1}$ Hospital General Universitario Alicante, Alicante, Spain; ${ }^{2}$ Hospital Denia Marina Salud, Alacant, Spain; ${ }^{3}$ Hospital Universitario del Vinalopó, \\ Alacant, Spain \\ Correspondence to: Julio Sesma. C/Pintor Baeza, 12, 03010, Alicante, Spain. Email: jsesmaromero@gmail.com.
}

\begin{abstract}
In recent years, the video-assisted thoracic surgery (VATS), and uniportal VATS approach has become the routine approach in numerous centers. Nevertheless, uniportal VATS learning curve is a challenge even for those surgeons with experience in multiportal VATS surgery. Among the surgeons who prefer the use of the multiportal VATS approach it is noteworthy that many of them are more comfortable through several ports because they feel this approach is more ergonomic. We present our routine programme of VATS surgery assisted by articulated arm (AVATS) for major resections, as a technique that allows ergonomic surgery for both, surgeon and first assistant and cooperative surgical field when is needed.
\end{abstract}

Keywords: Uniportal video-assisted thoracic surgery (uniportal VATS); VATS; VATS surgery assisted by articulated arm (AVATS); thoracoscopy; ergonomy; VATS anatomical resections

Received: 20 November 2018; Accepted: 27 January 2019; Published: 22 February 2019.

doi: 10.21037 shc. 2019.01 .08

View this article at: http://dx.doi.org/10.21037/shc.2019.01.08

\section{Introduction}

Video-assisted thoracic surgery (VATS) has meant an important change in the postoperative period of patients undergoing thoracic surgery $(1,2)$. In recent years, the uniportal VATS approach has become the routine approach in numerous centers (3), even in complex procedures such a sleeve resections (4) or anatomical segmentectomies (5). Uniportal VATS potentially attacks to a single intercostal space reducing pain and improving postoperative outcomes (6). Uniportal VATS learning curve is a challenge even for those surgeons with experience in multiportal VATS surgery (3). We describe our routine programme of VATS assisted by articulated arm (AVATS) for major resections, as a technique that allows ergonomic surgery for both, surgeon and first assistant.

\section{Operative technique}

The concept of AVATS surgery is to attend VATS with and articulated arm that holds the $30^{\circ}$ camera and allows ergonomic field of operation. There are several available systems (mechanic, pneumatic, or voice-controlled) (7). System consists of three point of articulation with a rotation of 180 degrees that is anchored to the surgical table (Figure $1 A)$.

During AVATS, the surgical approach is performed as in routine VATS. For upper pulmonary major procedures, the articulated arm is usually located on the same side of the first surgeon, anchoring its main stem at the height of the anterior superior iliac spine (ASIS) (Figure 1A). For lower procedures, the articulated arm can be placed on the side of the main surgeon, as well as on the opposite side, at the height of the utility incision (Figure 1B), depending on the preferences of the surgeon. For major mediastinal surgery, the arm is usually place in the same side than surgeon, near to the ASIS and is facilitated by $\mathrm{CO} 2$ collapse and is quite ergonomic with 3 ports approach (Figure 1C).

In major pulmonary resections, the position (both height 

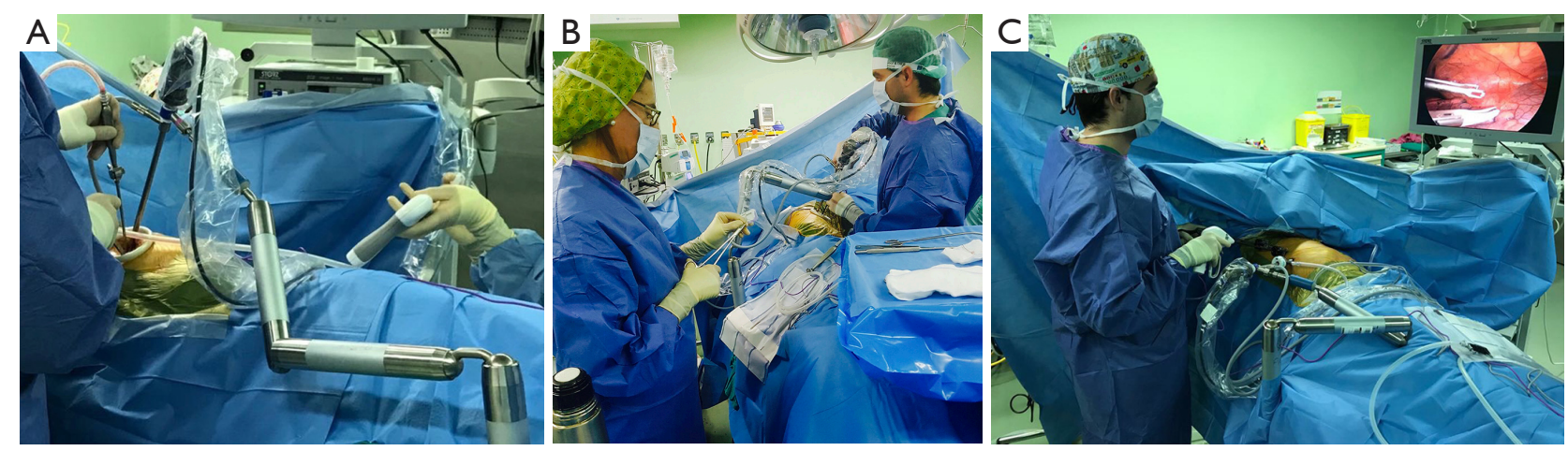

Figure 1 Ergonomic positions during AVATS major resections. (A) AVATS system position for major upper pulmonary resections; (B) uniportal AVATS approach for major lower pulmonary resections; (C) AVATS approach for major mediastinal surgery. AVATS, VATS surgery assisted by articulated arm.

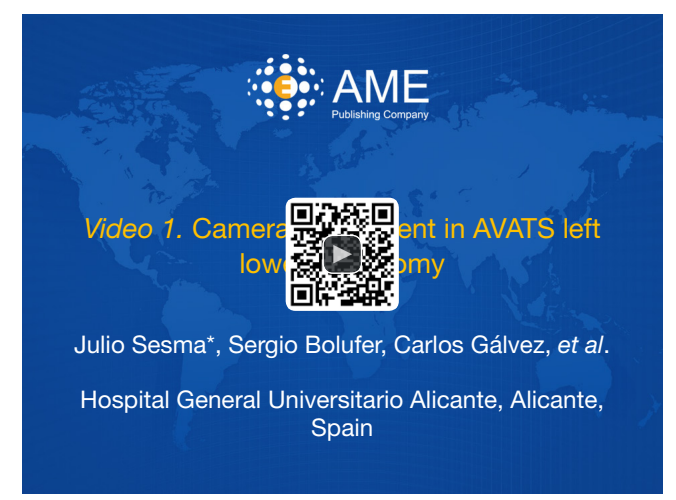

Figure 2 Camera adjustment in AVATS left lower lobectomy (8). AVATS, VATS surgery assisted by articulated arm.

Available online: http://www.asvide.com/article/view/30029

and rotation) of the main stem is modifiable whenever necessary, although usually it is enough with the fine adjustments made by the assistant on the 3 joints (Figure 2). In all cases, the adjustment of the articulated arm does not interfere with the usual handling of the 30 degree optics, allowing to modify the degrees whenever the assistant needs it. In pneumatic arm case, the movement is activated by a button that activates the pneumatic system connected to the nitrogen intake. The release of the assistant allows complex instrumentation through the VATS approach (uni or multiportal), making it possible for the assistant to also use both hands to help the main surgeon (Figure 3).

In experienced teams, almost every AVATS can be developed through unisurgeon technique (7). As during AVATS the surgeon is not fighting for space with the assistant, the position is more comfortable than in

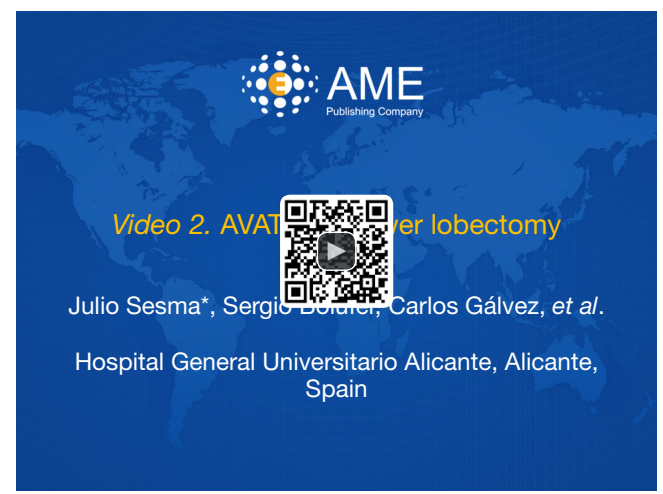

Figure 3 AVATS left lower lobectomy (9). AVATS, VATS surgery assisted by articulated arm.

Available online: http://www.asvide.com/article/view/30030

conventional VATS and more exigent situations as strong adhesions or systematic lymphadenectomy can be done through more ergonomic way (Figure $4 A$ ). In case of uniportal VATS approach, some interesting tricks as two instruments handed trick, self-holding instrument trick, two finger instrumentation trick and surgeon-assistant two handed advance instrumentation (Figure $4 B$ ) can facilitate the procedure.

In our initial experience, surgical time and perioperative complications are not affected by this approach. In addition, our activity was developed in its majority through uniportal AVATS, having appreciated greater fluidity and speed in the surgery since the assistant can collaborate actively in the procedure, comparing to conventional uniportal VATS.

The uniportal VATS major procedures of high complexity (lobectomies, anatomical segmentectomies or 

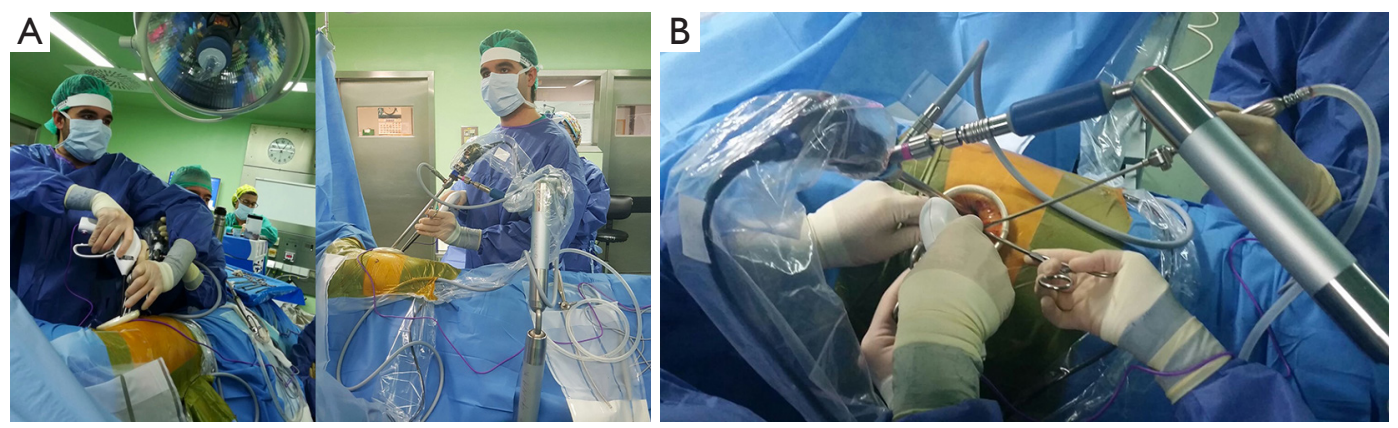

Figure 4 Biportal VATS vs. uniportal AVATS position while 4R dissection. (A) Biportal VATS vs. AVATS position while 4R dissection; (B) surgeon-assistant advance instrumentation. VATS, video-assisted thoracic surgery; AVATS, VATS surgery assisted by articulated arm.

extended procedures with bronchoplasty or angioplasty) were perceived by our assistants with a value $8-10$ (really hard or maximum effort) on the Borg CR-10 Scale, whereas during the use of the AVATS system are perceived at a level 1-2 (really easy or easy).

\section{Comments}

Ergonomic problems during VATS surgery have been previously described in the literature. Main problems remain in the fatigue of the legs, a static body position, a large working area and extreme movements of the upper limbs (10). Even more, through Uniportal VATS, the assistant have the challenge to ensure the quality of the image, assist the main surgeon and keep the camera straight simultaneously. It is well known that fatigue caused by holding the camera for a long time reduces the attention of the assistant and increases the uncertainty of the surgery (11). These ergonomics problems can be resolved following AVATS system, so the assistant remains free to be involved in the procedure, increasing attention, an active participation. In addition, AVATS system allows a completely immobile image, what sometimes is very difficult under conventional uniportal or multiportal VATS. The ergonomic benefit of the uniportal VATS compared to the multiportal approach has been evaluated in less complex procedures such as wedge-type resections $(12,13)$. This benefit is justified by viewing direction allowing better eye-hand-target axis and a posture that overload trapezius muscles instead of biceps flexion what minimized the fatigue (13). However, it is noteworthy that the main ergonomic problems of the uniportal VATS approach appears in procedures of longer duration and complexity (lobectomy, anatomical segmentectomy, major mediastinal resections), is difficult to keep the posture during the time without compromising the assistantship. Uniportal VATS major resections, due to the complexity and duration, are the context that most benefits from the AVATS system. A key point is that in uniportal AVATS procedures, eye-handtarget axis is well maintained but also is possible to avoid muscle overloading.

\section{Conclusions}

AVATS surgery increase ergonomics and optimization of surgical resources and is a very good tool to create more cooperation between surgeon and assistant. As the technique is just developed since less than 1 year, prospective studies are needed to assess economy and influence in the intraoperative complications, but in our experience, is a safe and feasible technique for surgeon who previously has already completed VATS learning curve.

\section{Acknowledgments}

Funding: None.

\section{Footnote}

Conflicts of Interest: All authors have completed the ICMJE uniform disclosure form (available at http://dx.doi. org/10.21037/shc.2019.01.08). The authors have no conflicts of interest to declare.

Ethical Statement: The authors are accountable for all aspects of the work in ensuring that questions related to the accuracy or integrity of any part of the work are 
appropriately investigated and resolved. All procedures performed in studies involving human participants were in accordance with the ethical standards of the institutional and/or national research committee(s) and with the Helsinki Declaration (as revised in 2013). Written informed consent was obtained from the patient for publication of this manuscript and any accompanying images.

Open Access Statement: This is an Open Access article distributed in accordance with the Creative Commons Attribution-NonCommercial-NoDerivs 4.0 International License (CC BY-NC-ND 4.0), which permits the noncommercial replication and distribution of the article with the strict proviso that no changes or edits are made and the original work is properly cited (including links to both the formal publication through the relevant DOI and the license). See: https://creativecommons.org/licenses/by-nc-nd/4.0/.

\section{References}

1. Paul S, Altorki NK, Sheng S, et al. Thoracoscopic lobectomy is associated with lower morbidity than open lobectomy. A propensity-matched analysis from the STS database. J Thorac Cardiovasc Surg 2010;139:366-78.

2. Sugi K, Kaneda Y, Esato K. Video-assisted thoracoscopic lobectomy achieves a satisfactory long-term prognosis in patients with clinical stage IA lung cancer. World J Surg 2000;24:27-31.

3. Martin-Ucar AE, Aragon J, Bolufer Nadal S, et al. The influence of prior multiport experience on the learning curve for single-port thoracoscopic lobectomy: a multicentre comparative study†. Eur J Cardiothorac Surg 2017;51:1183-7.

doi: $10.21037 /$ shc. 2019.01 .08

Cite this article as: Sesma J, Bolufer S, Gálvez C, Álvarez M, Lirio F, Córcoles JM, Del Campo JM, Maroto S, Galiana M, Navarro-Martínez J, Rivera MJ. Video-assisted thoracic surgery assisted by articulated arm (AVATS): a new way towards ergonomics and optimization of surgical resources. Shanghai Chest 2019;3:12.
4. Gonzalez-Rivas D, Fernandez R, Fieira E, et al. Uniportal video-assisted thoracoscopic bronchial sleeve lobectomy: first report. J Thorac Cardiovasc Surg 2013;145:1676-7.

5. González-Rivas D, Lirio F, Sesma J. Uniportal anatomic combined unusual segmentectomies. J Vis Surg 2017;3:91.

6. Migliore M. Efficacy and safety of single-trocar technique for minimally invasive surgery of the chest in the treatment of noncomplex pleural disease. J Thorac Cardiovasc Surg 2003;126:1618-23.

7. Gonzalez-Rivas D. Unisurgeon uniportal video-assisted thoracoscopic surgery lobectomy. J Vis Surg 2017;3:163.

8. Sesma J, Bolufer S, Gálvez C, et al. Camera adjustment in AVATS left lower lobectomy. Asvide 2019;6:043. Available online: http://www.asvide.com/article/view/30029

9. Sesma J, Bolufer S, Gálvez C, et al. AVATS left lower lobectomy. Asvide 2019;6:044. Available online: http:// www.asvide.com/article/view/30030

10. Kranenburg, Gossot. Ergonomic problems encountered during video-assisted thoracic surgery. Minim Invasive Ther Allied Technol 2004;13:147-55.

11. Bertolaccini L, Rocco G, Pardolesi A, Solli P. The Geometric and Ergonomic Appeal of Uniportal Video-Assisted Thoracic Surgery. Thorac Surg Clin 2017;27:331-8.

12. Bertolaccini L, Viti A, Terzi A, et al. Geometric and ergonomic characteristics of the uniportal video-assisted thoracoscopic surgery (VATS) approach. Ann Cardiothorac Surg 2016;5:118-22.

13. Bertolaccini L, Viti A, Terzi A. Ergon-trial: ergonomic evaluation of single-port access versus three-port access video-assisted thoracic surgery. Surg Endosc 2015;29:2934-40. 